\title{
On the stated association between labour epidural analgesia and risk of autism spectrum disorder in offspring
}

\author{
Bryan A. Glezerson, MD, FRCPC (D) - Vatsal Trivedi, MD, FRCPC • Daniel I. McIsaac, MD, \\ MPH, FRCPC
}

Received: 27 October 2020/Revised: 7 November 2020/Accepted: 9 November 2020/Published online: 20 November 2020

(C) Canadian Anesthesiologists' Society 2020

\section{To the Editor,}

We read with interest the retrospective study from Qiu et al. in the journal JAMA Pediatrics, examining the association between labour epidural analgesia (LEA) and the risk of autism spectrum disorder (ASD) in offspring. ${ }^{1} \mathrm{~A}$ collective concern about the clinical and socio-cultural implications of the report has been expressed by physician groups around the world, including in Canada. ${ }^{2} \mathrm{We}$ welcome the opportunity to discuss certain challenges in the interpretation of this study. Confidence that any nonrandomized, retrospective study of treatment can produce a causal estimate requires accurate ascertainment of exposure and outcome, and robust control for sources of bias. We respectfully suggest that both misclassification of the outcome and inadequate control for indication bias may have led to an effect estimate that reflects unmeasured bias instead of true causal effects.

Bryan A. Glezerson and Vatsal Trivedi contributed equally to the conception and writing of this manuscript.

This letter is accompanied by an editorial. Please see Can J Anesth 2021; this issue.

\section{B. A. Glezerson, MD, FRCPC ( $\square)$.}

Krembil Brain Institute, Toronto Western Hospital, University of Toronto, Toronto, ON, Canada

e-mail: bryanglezerson@gmail.com

V. Trivedi, MD, FRCPC

Interdepartmental Division of Critical Care Medicine, University of Toronto, Toronto, ON, Canada

\section{I. McIsaac, MD, MPH, FRCPC}

Department of Anesthesiology and Pain Medicine, University of Ottawa and The Ottawa Hospital, Ottawa, ON, Canada
Non-randomized studies of treatment are at risk of indication bias. In the Qiu et al. study, even after adjustment, limitations in available data and analytic choices suggest that bias likely remains. As little is known with certainty about the causal risk factors for ASD, many relevant variables likely were not measured. Since both groups differed significantly across measured variables at baseline, it is likely that unmeasured variables were similarly unbalanced. While propensity-based techniques led to balance in measured variables, these techniques cannot address limitations in variable coding. Many variables were dichotomous, including a composite of "history of comorbidity". ${ }^{3}$ This will not reflect differences in disease severity, ${ }^{3}$ or the likelihood of unique associations of different comorbidities with the outcome. While Qiu et al. calculate that a single unmeasured variable would at least require a 1.76-fold relative association with exposure (i.e., LEA) and outcome (i.e., ASD) to nullify their findings, we submit that the multi-dimensional limitations of the data set and analysis create far more concern that the effect estimate is biased away from the null, compared with any reassurance of a "true" association conferred by an E-value. ${ }^{\mathrm{A}}$

Accurate coding of the outcome itself underlies the validity of outcome measures in database research. Previous publications of ASD code validity have reported figures for positive predictive value (PPV; 88\%), ${ }^{4}$

\footnotetext{
A The E-value denotes the minimum degree of association (expressed as a risk ratio) that a hypothetical unmeasured confounder must share with both the exposure and the outcome in question to nullify an experimental effect estimate between said exposure and outcome (Ding P, VanderWeele TJ. Sensitivity analysis without assumptions. Epidemiology 2016; 27: 368-77). The E-value is thus a metric for appraising the potential influence of unmeasured confounding on causal inference.
} 
sensitivity (69\%), ${ }^{5}$ and specificity $(77 \%),{ }^{5}$ each suggesting inadequate validity for the current study. To use these values in a subsequent study, the study population must resemble the cohort in which the code was validated. As PPV varies with prevalence, a PPV of $88 \%$ from a validation study with $45 \%$ prevalence is difficult to generalize to a setting with 1-2\% ASD prevalence (as in the Qiu et al. study). Considering the aforementioned variables, the post-test probability in the Qiu et al. study of true ASD with an ASD code is $<5 \%$, while a $0.5 \%$ probability of true ASD remains in the absence of a code.

In the context of limited biologic plausibility, important sources of residual confounding, and outcome misclassification risk, the probability of a true causal association between LEA and ASD appears low and can only be reliably explored in a randomized-controlled trial.

Disclosures None.

\section{Funding statement None.}

Editorial responsibility This submission was handled by Dr. Hilary P. Grocott, Editor-in-Chief, Canadian Journal of Anesthesia.

\section{References}

1. Qiu C, Lin JC, Shi JM, et al. Association between epidural analgesia during labor and risk of autism spectrum disorders in offspring. JAMA Pediatr 2020; DOI: https://doi.org/10.1001/ jamapediatrics.2020.3231.

2. McKeen DM, Zaphiratos V; Canadian Anesthesiologists' Society. Lack of evidence that epidural pain relief during labour causes autism spectrum disorder: a position statement of the Canadian Anesthesiologists' Society. Can J Anesth 2020; DOI: https://doi. org/10.1007/s12630-020-01840-z.

3. Ray JG, Burrows RF, Burrows EA, Vermeulen MJ. MOS HIP: McMaster outcome study of hypertension in pregnancy. Early Hum Dev 2001; 64: 129-43.

4. Burke JP, Jain A, Yang W, et al. Does a claims diagnosis of autism mean a true case? Autism 2014; 18: 321-30.

5. Dodds L, Spencer A, Shea $S$, et al. Validity of autism diagnoses using administrative health data. Chronic Dis Can 2009; 29: 102-7.

Publisher's Note Springer Nature remains neutral with regard to jurisdictional claims in published maps and institutional affiliations. 